OPEN ACCESS

Edited by:

Walter Adriani,

Istituto Superiore di Sanità (ISS), Italy

Reviewed by:

Maria Morena,

University of Calgary, Canada

Antonia Manduca,

Aix-Marseille Université, France

${ }^{*}$ Correspondence:

Saoirse E. O'Sullivan

mbzso@nottingham.ac.uk

Received: 24 August 2018 Accepted: 22 October 2018

Published: 26 November 2018

Citation:

Stone NL, Millar SA, Herrod PJJ, Barrett DA, Ortori CA, Mellon VA and O'Sullivan SE (2018) An Analysis of Endocannabinoid Concentrations and Mood Following Singing and

Exercise in Healthy Volunteers.

Front. Behav. Neurosci. 12:269.

doi: 10.3389/fnbeh.2018.00269

\section{An Analysis of Endocannabinoid Concentrations and Mood Following Singing and Exercise in Healthy Volunteers}

\author{
Nicole L. Stone ${ }^{1}$, Sophie A. Millar ${ }^{1}$, Philip J. J. Herrod ${ }^{1}$, David A. Barrett ${ }^{2}$, \\ Catharine A. Ortori ${ }^{2}$, Valerie A. Mellon ${ }^{3}$ and Saoirse E. O'Sullivan ${ }^{1 *}$
}

'Division of Medical Sciences and Graduate Entry Medicine, School of Medicine, University of Nottingham, Nottingham, United Kingdom, ${ }^{2}$ Centre for Analytical Bioscience, Advanced Materials and Healthcare Division, School of Pharmacy, University of Nottingham, Nottingham, United Kingdom, ${ }^{3}$ BBC Studios "Trust Me I'm a Doctor", BBC Scotland, Glasgow, United Kingdom

The euphoric feeling described after running is, at least in part, due to increased circulating endocannabinoids (eCBs). eCBs are lipid signaling molecules involved in reward, appetite, mood, memory and neuroprotection. The aim of this study was to investigate whether activities other than running can increase circulating eCBs. Nine healthy female volunteers (mean 61 years) were recruited from a local choir. Circulating eCBs, haemodynamics, mood and hunger ratings were measured before and immediately after 30 min of dance, reading, singing or cycling in a fasted state. Singing increased plasma levels of anandamide (AEA) by $42 \%(P<0.05)$, palmitoylethanolamine (PEA) by 53\% $(P<0.01)$ and oleoylethanolamine (OEA) by 34\% $(P<0.05)$ and improved positive mood and emotions $(P<0.01)$, without affecting hunger scores. Dancing did not affect eCB levels or hunger ratings, but decreased negative mood and emotions $(P<0.01)$. Cycling increased OEA levels by $26 \%(P<0.05)$ and tended to decrease how hungry volunteers felt, without affecting mood. Reading increased OEA levels by 28\% $(P<0.01)$ and increased the desire to eat. Plasma AEA levels were positively correlated with how full participants felt $(P<0.05)$. Plasma OEA levels were positively correlated with positive mood and emotions $(P<0.01)$. All three ethanolamines were positively correlated with heart rate $(\mathrm{HR} ; P<0.0001)$. These data suggest that activities other than running can increase plasma eCBs associated with changes in mood or appetite. Increases in eCBs may underlie the rewarding and pleasurable effects of singing and exercise and ultimately some of the long-term beneficial effects on mental health, cognition and memory.

Keywords: endocannabinoids, anandamide, human, clinical, high, mood, singing and dancing

Abbreviations: 2-AG, 2-arachidonoylglycerol; AEA, anandamide; BBB, blood brain barrier; BDNF, brain derived neurotrophic factor; eCBs, endocannabinoids; LC-ESI-MS-MS, electrospray ionization liquid chromatography/mass spectrometry; OEA, oleoylethanolamine; PEA, palmitoylethanolamine. 


\section{INTRODUCTION}

The classic "runners high" is described as the sense of well-being and mood elevation associated with moderate distance running. Other typical indicators include a decrease in anxious thinking (anxiolytic), positive emotions/mood (euphoria), reduced pain perception (analgesia) and a feeling of increased endurance (Sparling et al., 2003; Dietrich and McDaniel, 2004; Tsatsoulis and Fountoulakis, 2006; Raichlen et al., 2012). To explain these positive effects post-exercise, attention was directed to the endocannabinoid (eCB) system, and a number of groups have found significant correlations between physical activity, mood and elevated eCB levels. Interestingly, the majority of studies have only observed significant rises in the first identified eCB, anandamide (AEA; Sparling et al., 2003; Heyman et al., 2012; Raichlen et al., 2013), whilst the reports analyzing 2-arachidonylglycerol (2-AG) levels post-exercise have been less clear. Heyman et al. (2012) reported no change in circulating 2-AG levels after cycling. However, Brellenthin et al. (2017) showed that 2-AG and AEA were significantly increased in a study analyzing the effects of preferred (self-selected) and prescribed (70\%-75\% of max) exercise on eCB levels and mood.

The eCB system consists of the cannabinoid receptors 1 and $2\left(\mathrm{CB}_{1}\right.$ and $\left.\mathrm{CB}_{2}\right)$, eCBs, and the enzymes that are responsible for their synthesis and breakdown (Devane et al., 1992; Mechoulam et al., 1995; De Petrocellis and Di Marzo, 2009). AEA and 2-AG are partial agonists of $\mathrm{CB}_{1}$ and $\mathrm{CB}_{2}$, whilst palmitoylethanolamine (PEA) and oleoylethanolamine (OEA) share similar synthesis and degradation mechanisms, without directly interacting with these receptors themselves (Hansen et al., 2000; Okamoto et al., 2004). Instead, these molecules interact with other receptors, primarily peroxisome proliferator-activated receptor alpha (PPAR- $\alpha)$ and transient receptor potential cation channel subfamily $\mathrm{V}$ member 1 (TRPV1; Ahern, 2003; Fu et al., 2003; Lo Verme et al., 2005a,b; Karwad et al., 2017). eCB signaling mediates a number of physiological and psychological processes including emotional responses, cognition, memory, motor behavior, feeding and energy consumption (Berger and Motl, 2000; Cota et al., 2003; Cota, 2007; Brellenthin et al., 2017). Studies have also established prominent roles of $\mathrm{eCB}$ signaling in the positive reinforcement in reward driven activities such as masturbation, arousal, bingeeating and social interactions in humans (Klein et al., 2012; Monteleone et al., 2015, 2017; Fuss et al., 2017).

Singing and dancing, especially as a group activity, are associated with positive mood in humans (Zajenkowski et al., 2015; Pearce et al., 2016; Tarr et al., 2016; Schladt et al., 2017). However, little has been studied to elucidate how these positive emotions are mediated. Recently, Hahn et al. (2017) studied the relationship between song practice and the eCB system in European starlings. They found a significant positive correlation between conditioned place preference (a measure of reward and song production), the number of songs a bird produced and the expression of $\mathrm{CB}_{1}$ in areas of the brain associated with reward, primarily the ventral tegmental area. Therefore suggesting a role for eCB signaling in singing and reward (Hahn et al., 2017; Riters et al., 2017). In humans, singing has been studied as a therapy for long-term disorders such as Alzheimer's (to improve cognition, memory and long-term pain), chronic obstructive pulmonary disease, as well as to improve mood in conditions such as anxiety and depression (Reagon et al., 2016; Kang et al., 2017). Similarly, dancing has been explored as a potential therapy for cognitive and emotional dysfunction in conditions such as depression, dementia and Parkinson's. In a systematic review of 11 studies, Kiepe et al. (2012) found that depression and psychological distress were reduced by dance therapy in patients suffering from Parkinson's, diabetes, breast cancer or heart failure. Dance therapy in a group of 60 students also significantly reduced depression over a period of 12 weeks (Akandere and Demir, 2011). To date, no study has assessed singing or dancing and whether they modulate eCB levels in humans and whether that correlates to an improved mood. Given that mood is central in the measure of overall psychological wellbeing, low intensity activities that can positively modulate mood could be useful therapeutic tools in numerous conditions such as depression, anxiety and stress, especially if a patient cannot undertake moderate/higher intensity exercise.

The purpose of this study was to investigate whether activities other than running can give you a measurable "high" through changes in circulating eCBs levels. We examined activities that are associated with euphoria (singing and dancing) as well as an exercise regime other than running (cycling), with the hypothesis that these activities would increase plasma eCB levels. Quiet reading was used as a control condition. A secondary objective of this study was to establish whether there was a link between cycling, dancing, singing and reading with regards to mood and hunger ratings.

\section{MATERIALS AND METHODS}

\section{Participants}

All procedures were approved by the University of Nottingham Faculty of Health Sciences ethics committee, and were carried out according to the declaration of Helsinki. Nine healthy post-menopausal female volunteers (age range 55-67, mean 61 years) were recruited from a local choir as people who enjoyed singing and exercise. The inclusion criteria were that volunteers be non-smokers, in good physical health, accustomed to singing in a group, and also enjoy exercise. Volunteers gave written informed consent prior to participation. The medications taken included antihypertensives $(n=2)$, antacids $(n=2)$, antidepressants/anti-anxiety medication $(n=2)$, HRT $(n=1)$, and an inhaler for asthma $(n=1)$.

Subjects arrived fasted (feeding affects plasma eCB levels; Monteleone et al., 2012) with no consumption of caffeine and this was verbally confirmed on arrival at the study facility. Participants were also asked to refrain from any exercise prior to attending the laboratory. Volunteers were unaware of the activity they were to perform on a given day until all baseline measurements were made to avoid any anticipatory effects.

\section{Study Days}

Subjects came to the test site on four occasions between $8 \mathrm{am}$ and $10 \mathrm{am}$ in loose fitting sportswear. Each day, 
individuals were asked to complete two questionnaires before and after completing the activity. A visual analog scale (VAS) questionnaire was used to assess how hungry subjects were feeling on a scale of 1-10, using the questions "how hungry do you feel?", "how full are you?", "how much food could you eat?" and "how strong is your desire to eat?". A positive and negative affect schedule (PANAS) questionnaire was used to assess subject's mood before and after each activity using the following scoring system: 1 = "very slightly or not at all," $2=$ "a little," 2 = "moderately," 4 = "quite a bit" and 5 = "extremely;" Watson et al., 1988; Crawford and Henry, 2004). Positive affect score was calculated by adding the positive emotional responses and the negative affect score was calculated based on the addition of the negative affect scores.

Blood pressure was measured by oscillometry with the participant seated according to the British Hypertension Society guidelines, and heart rate (HR) was taken prior to commencing the activity and immediately after finishing the activity. Blood pressure and HR measurements were taken as the average over three (pre-activity) or 2 (post-activity) measurements. Blood draws (approximately $5 \mathrm{~mL}$ ) were taken before commencing the activity and immediately after finishing the activity into pre-chilled K2-EDTA (Ethylenediaminetetraacetic acid) tubes and immediately placed on ice. After collection, blood was centrifuged at $2,000 \mathrm{~g}$ for $15 \mathrm{~min}$ at $4^{\circ} \mathrm{C}$, plasma was removed and aliquoted, and immediately snap frozen in liquid nitrogen. Samples were stored at $-80^{\circ} \mathrm{C}$ until subsequent analysis.

After the baseline measurements were made, volunteers were informed of the activity they were to perform. On day 1, volunteers did a supervised $30 \mathrm{~min}$ dance exercise class preceded by a 5 min warm up, to upbeat music. On day 2, volunteers did $30 \mathrm{~min}$ of supervised quiet reading (of boiler and dishwasher catalogs) to classical music. On day 3, volunteers for $30 \mathrm{~min}$ choir practice led by their choral director. On day 4 , volunteers did a 30 min spin class (cycling) with a qualified instructor from the University of Nottingham Sports facility, with a 5 min warm up to upbeat music. All activities were performed as a group.

\section{eCB Quantification}

eCB analysis was based on the method as described by Richardson et al. (2007). Samples were thawed and $100 \mu \mathrm{L}$ of internal standard of 2-AG-d8 $(10 \mu \mathrm{M})$ and $15 \mu \mathrm{L}$ of AEA-d8 $(28 \mu \mathrm{M})$ were added to a $0.4 \mathrm{~mL}$ aliquot of each plasma sample or blank sample $(0.4 \mathrm{~mL}$ water $)$ vortexed briefly. Ethyl acetate:hexane $(9: 1 \mathrm{v} / \mathrm{v})$ was added to each sample and subjected for a slow vortex $(10 \mathrm{~min})$ and centrifuged for $13,000 \mathrm{rpm}, 10 \mathrm{~min}, 4^{\circ} \mathrm{C}$. The supernatants were transferred and the procedure was repeated. Supernatants were then pooled and evaporated using a centrifugal evaporator. Prior to analysis, each sample extract was reconstituted in $100 \mu \mathrm{L}$ of acetonitrile (ACN). Standards for AEA, 2-AG, PEA, OEA, N-(2-hydroxyethyl)-9Z-octadecenamide), arachidonyl ethanolamide-d8 (N-(2-Hydroxyethyl)-5Z, 8Z, 11Z, 14Zeicosatetraenamide-d8, AEA-d8) and 2-arachidonyl glycerol-d8 (2-AG-d8, (5Z, 8Z, 11Z, 14Z)-5, 8, 11, 14-Eicosatetraenoic acidd8, 2-hydroxy-1-(hydroxymethyl)ethyl ester-d8) were purchased from Cambridge BioSciences, UK.
Following sample preparation, $10 \mu \mathrm{L}$ of final sample extract was analyzed using liquid chromatography electrospray ionisation mass spectrometry (LC-ESI-MS/MS). The HPLC system used was a modular Shimadzu Vp series LC (Shimadzu, Milton Keynes, UK), with pumps, chilled autosampler and column oven. The HPLC column used was an ACE $3 \mathrm{C} 8$ $(100 \times 2.1 \mathrm{~mm}, 3 \mathrm{~mm})$ with guard column. The mobile phase A was water with $1 \mathrm{~g} / \mathrm{L}$ ammonium acetate and $0.1 \%$ formic acid and mobile phase B was ACN with $1 \mathrm{~g} / \mathrm{L}$ ammonium acetate and $0.1 \%$ formic acid pre-dissolved in $10 \% \mathrm{H}_{2} \mathrm{O}$. The flow rate was $300 \mu \mathrm{L} / \mathrm{min}$. The MS system used was a SCIEX 4000 QTrap triple quadrupole mass spectrometer (Sciex, Warrington, UK) operated in electrospray positive multiple reaction monitoring mode. Quantification was performed using Analyst 1.6 and identification of each compound in plasma was confirmed by LC retention times of each standard and precursor and product ion $\mathrm{m} / \mathrm{z}$ ratios. The peak area of each analyte is compared to a known amount of standard to determine the amount of target compound present.

2-AG in these samples were below the limit of quantification with our methodology in the plasma samples and the data has not been reported.

\section{Statistical Analysis}

Data is presented as a scatter plot with mean \pm SEM. Data sets were compared by paired Student's $t$-test pre and post-activity. Correlations between plasma eCBs levels and hunger ratings, cardiovascular parameters or mood pre and post-activities were analyzed by linear regression. A quality control check was performed by a separate researcher on data entry.

\section{RESULTS}

All but one of the participants completed the study in full; one participant was unable to finish the cycling activity and did not have a final blood draw or complete the surveys. Thus nine participates were in the final comparison, except for the cycling activity where $n=8$.

\section{Haemodynamics}

Thirty minutes of dancing significantly increased HR $\left(t_{(8)}=4.894, P<0.01\right.$, Figure 1A) and decreased diastolic blood pressure $\left(t_{(8)}=2.764, P<0.05\right.$, Figure 1I). Thirty minutes of reading caused a small but significant reduction in HR $\left(t_{(8)}=3.736, P<0.01\right.$, Figure 1B). Thirty minutes of singing increased systolic blood pressure $\left(t_{(8)}=5.66, P<0.001\right.$, Figure 1G). Thirty minutes of cycling significantly increased $\operatorname{HR}\left(t_{(7)}=7.314, P<0.001\right.$, Figure 1D) and decreased diastolic blood pressure $\left(t_{(7)}=2.567, P<0.05\right.$, Figure 1L).

\section{Hunger Scores}

The only significant change in hunger and appetite scores were observed after $30 \mathrm{~min}$ of reading when volunteers reported a significantly higher desire to eat (Figure 2N). Volunteers tended to have reduced hunger ratings after dancing, singing and cycling (Figure 2), but this only reached near significance for 

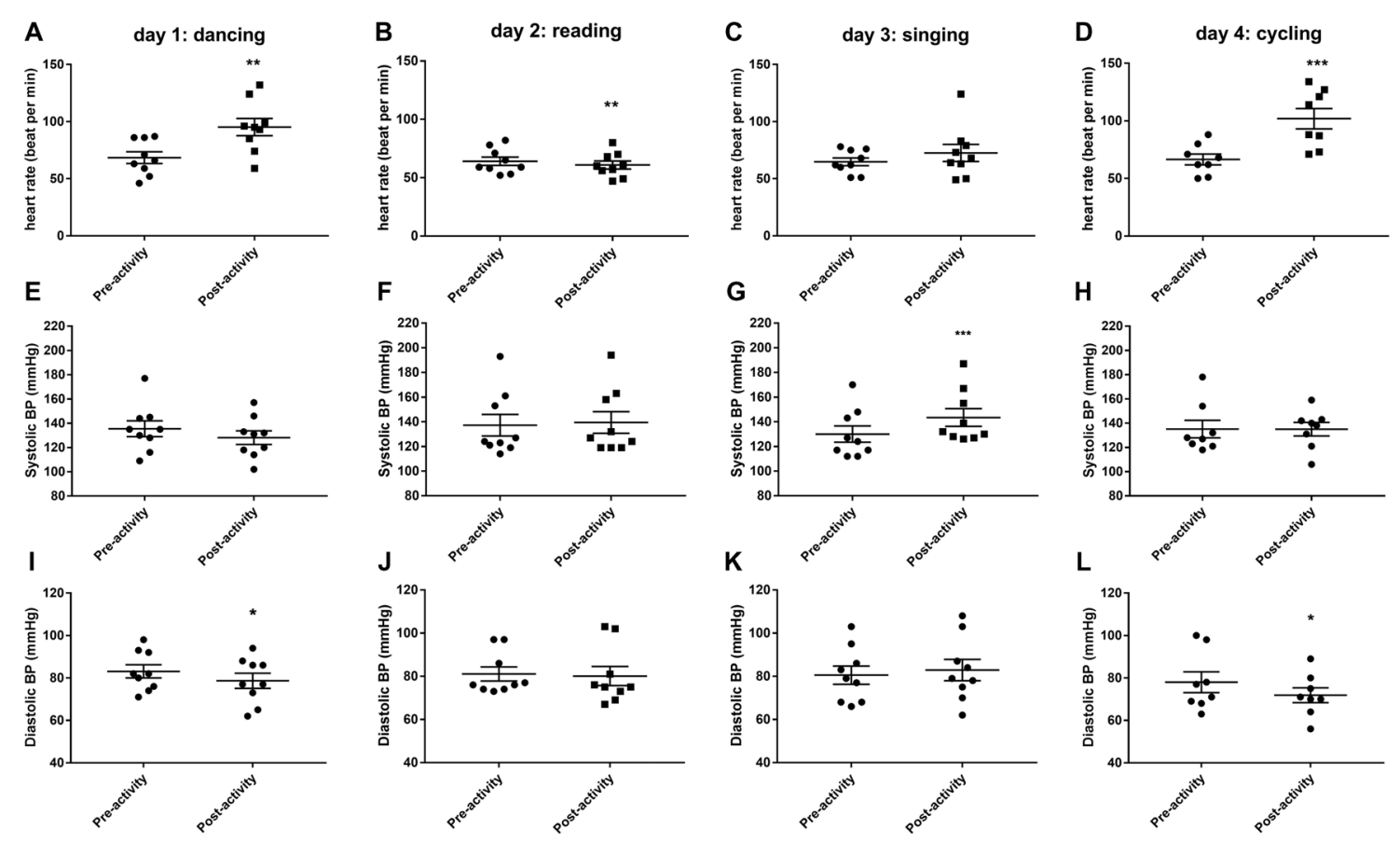

FIGURE 1 | Changes in cardiovascular parameters (heart rate, HR; A-D), systolic blood pressure (E-H) and diastolic blood pressure (I-L) before and after 30 min activity (dancing, reading, singing or cycling) in nine healthy female volunteers. Data is presented as a scatter plot with mean \pm SEM. Data sets were compared by paired Student's $t$-test pre and post-activity $\left({ }^{*} P<0.05,{ }^{* *} P<0.01\right.$ and $\left.{ }^{* * *} P<0.001\right)$.

the question "how hungry do you feel?" immediate post-cycling $\left(t_{(7)}=2.348, P=0.0512\right.$, Figure 2D).

\section{Mood Scores}

Dancing decreased negative mood and emotions $\left(t_{(8)}=3.671\right.$, $P<0.01$, Figure 3E), while reading decreased positive mood and emotions $\left(t_{(8)}=5.751, P<0.001\right.$, Figure 3B). Only singing was found to significantly improve positive mood and emotions $\left(t_{(8)}=4.951, P<0.01\right.$, Figure 3C) and also tended to decrease negative mood and emotions (eight out of nine volunteers reported a lower NAS post-singing, Figure 3E). Cycling has no effect on mood ratings.

\section{Plasma Levels of Endocannabinoids}

Dancing had no effect on circulating levels of eCBs measured immediately the activity, although there was a trend for AEA and OEA levels to be increased (Figures 4A,E). Thirty minutes of reading significantly increased plasma OEA levels $\left(t_{(8)}=4.586\right.$, $P<0.01$, Figure 4F) and tended to increase PEA levels $\left(t_{(8)}=2.02, P=0.078\right.$, Figure 4J). Singing significantly increased the plasma levels of all eCBs measurable; AEA $\left(t_{(8)}=3.049\right.$, $P<0.05$, Figure 4C), OEA $\left(t_{(8)}=4.81, P<0.01\right.$, Figure 4G) and PEA $\left(t_{(8)}=3.319, P<0.05\right.$, Figure $\left.4 \mathrm{~K}\right)$. OEA levels were also increased after $30 \mathrm{~min}$ cycling $\left(t_{(6)}=3.594, P<0.05\right.$, Figure $\left.4 \mathbf{H}\right)$.

At baseline (before activities started) across all 4 days, there was a significant positive correlation between plasma OEA levels and the rating for "how much food could you eat?" $\left(r^{2}=0.2226\right.$, $F=9.16, P<0.01)$ and positive mood and emotions $\left(r^{2}=0.1355\right.$,
$F=5.172, P<0.05)$. Resting HR was positively correlated with both plasma AEA $\left(r^{2}=0.3363, F=16.72, P<0.001\right)$ and PEA $\left(r^{2}=0.169, F=6.711, P<0.05\right)$ levels.

Across all days and time points (pre- and post-activity), plasma AEA levels were positively correlated with the rating for "how full are you?" ( $r^{2}=0.0626, F=4.472, P<0.05$, Figure 5A), and plasma OEA levels tended to be positively correlated with the rating for "how much food could you eat?" $\left(r^{2}=0.0404\right.$, $F=2.821, P=0.097$, Figure 5B) and "how strong is your desire to eat?" $\left(r^{2}=0.04624, F=3.248, P=0.076\right.$, Figure 5C) and with increased ratings for positive mood and emotion $\left(r^{2}=0.1269\right.$, $F=9.879, P<0.01$, Figure 5D). All three ethanolamines were positively correlated with HR (AEA: $r^{2}=0.4394, F=53.3$, $P<0.0001$, Figure 5E; OEA: $r^{2}=0.2639, F=24.37, P<0.0001$, Figure 5F and PEA: $r^{2}=0.2093, F=18, P<0.0001$, Figure 5G).

\section{DISCUSSION}

It is well reported that running is correlated with mood elevation. These positive effects have been attributed to an evolutionary trait, where positive re-enforcement ultimately led to increased food foraging, survival and subsequent passing of relevant genes to offspring and have recently been attributed, at least in part, to increases in eCBs (Bramble and Lieberman, 2004; Raichlen et al., 2012). Our study aimed to examine whether activities other than running also increase eCBs and enhance mood. We have shown for the first time that singing significantly increases levels of AEA, OEA and PEA in healthy post-menopausal females and 


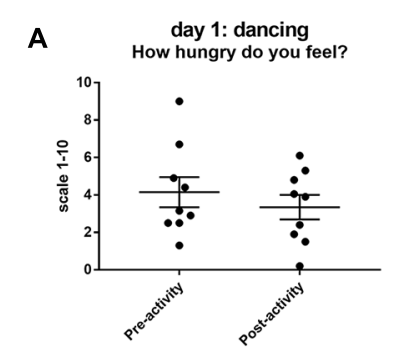

E

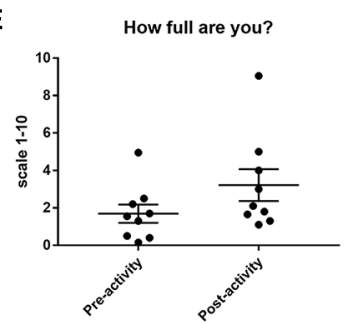

I

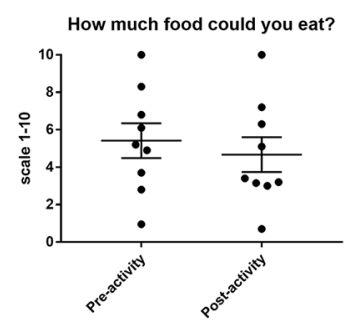

M

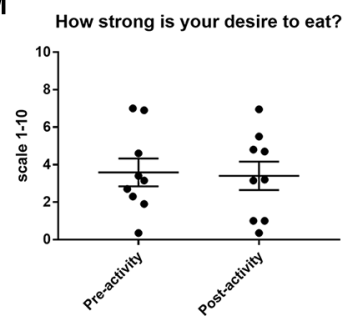

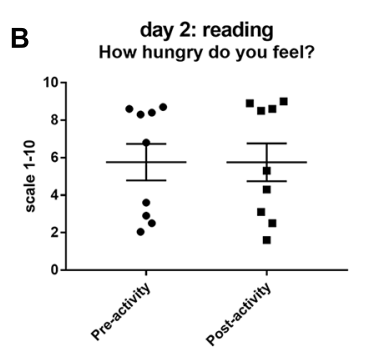

F

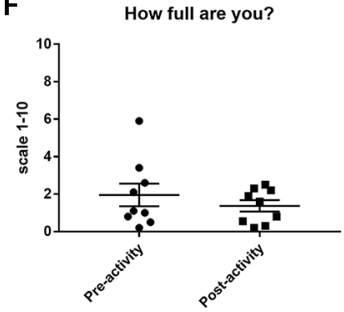

J

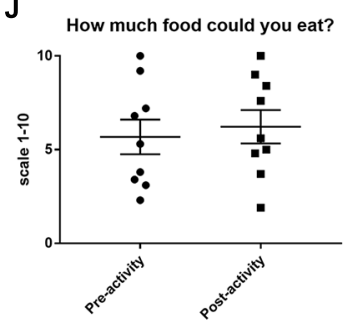

$\mathbf{N}$

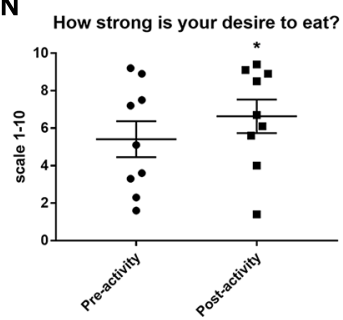

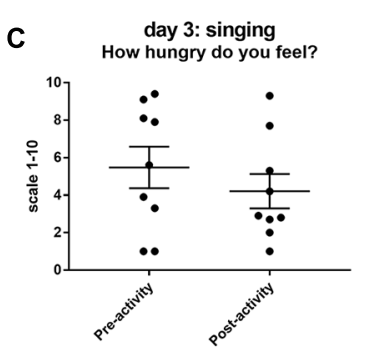

G

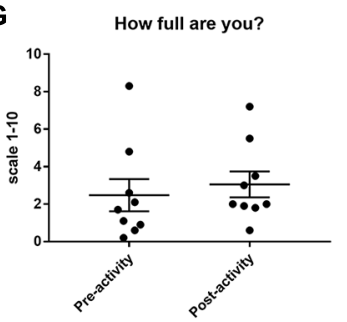

K

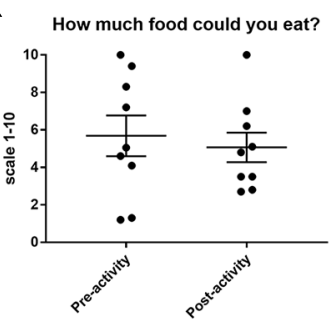

O

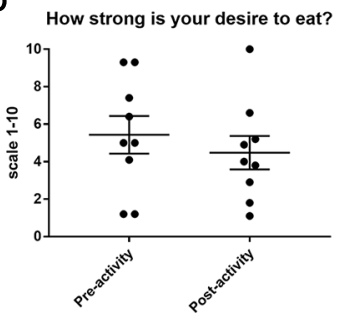

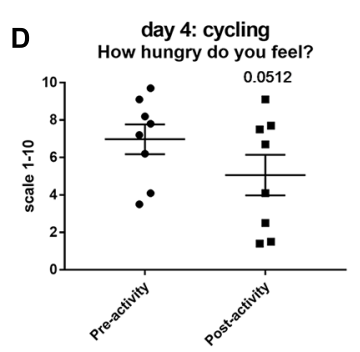

H How full are you?

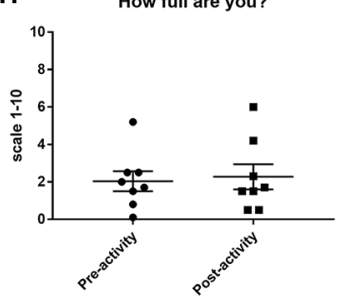

L

How much food could you eat?

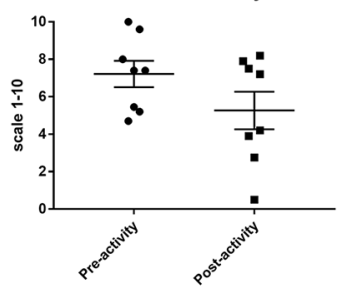

$\mathbf{P}$

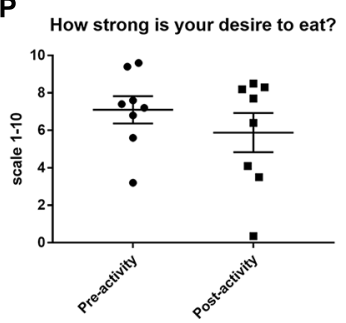

FIGURE 2 | Changes in hunger and appetite scores as assessed using a visual analog scale (VAS) (1-10) before and after 30 min activity (dancing (A,E,L,M), reading $(\mathbf{B}, \mathbf{F}, \mathbf{J}, \mathbf{N})$, singing $(\mathbf{C}, \mathbf{G}, \mathbf{K}, \mathbf{O})$ or cycling $(\mathbf{D}, \mathbf{H}, \mathbf{L}, \mathbf{P})$ in nine healthy female volunteers. Data is presented as a scatter plot with mean \pm SEM. Data sets were compared by paired Student's $t$-test pre and post-activity $(* P<0.05)$.

enhanced mood. Dancing (on mood) and cycling (on eCBs) also had positive effects in this group. Although singing was the most beneficial activity in this study, this is likely to reflect the fact that the volunteers were recruited from local choirs and already find this an enjoyable activity. These data provide biochemical evidence of an increase in novel signaling messengers known to improve mood, reduce stress and anxiety, enhance memory, protect brain function and reduce pain.

Singing, in particular group singing, has been associated with an increase in positive mood and improved immune function in humans (Kreutz et al., 2004; Schladt et al., 2017). Choir singing also enables social interactions, exhibiting a greater benefit to mood than singing alone (Schladt et al., 2017). Our results also demonstrate that singing increases mood, and also for the first time that singing increasing circulating levels of AEA, OEA and PEA. As AEA is a partial agonist of $\mathrm{CB}_{1}$ and has full agonist activity at TRPV1, an increase in the levels of AEA post activity could therefore facilitate increases in positive emotions, as well as anxiolytic and analgesic effects (Chapman et al., 2009; Starowicz et al., 2012). Levels of OEA post activity were correlated with a decrease in hunger and desire to eat. This supports previous data that OEA attenuates food consumption and increase lipolysis and energy expenditure (Lo Verme et al., 2005a,b). In vivo studies conducted in mice have also suggested beneficial neuroprotective effects of OEA, this protective effect could potentially be translated to humans and warrants further study (Galan-Rodriguez et al., 2009; Zhou et al., 2012; Yang et al., 2015). An abundance of evidence has supported PEA as a potential therapy for neurological and inflammatory disorders, particularly those associated with pain (Costa et al., 2008; Keppel Hesselink, 2012; Esposito and Cuzzocrea, 2013). PEA has also been taken into clinical trials, whereby $600 \mathrm{mg}$ of PEA was shown to be effective in various pain states, without exhibiting any safety issues 

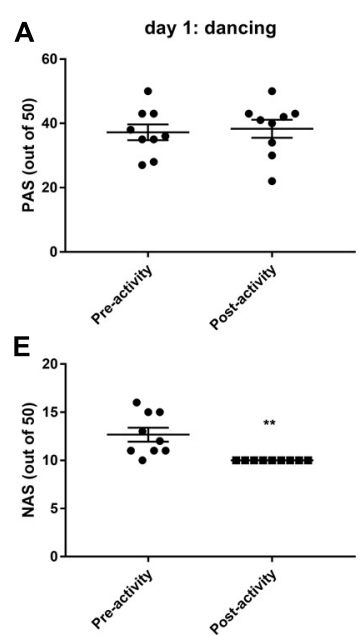

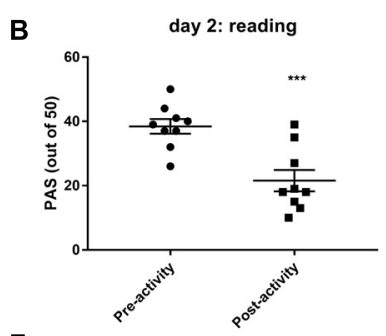

$\mathbf{F}$

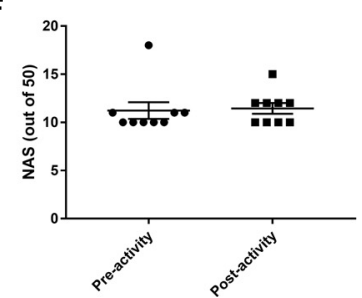

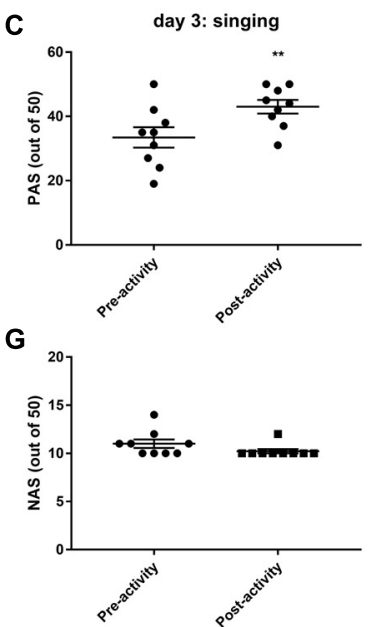
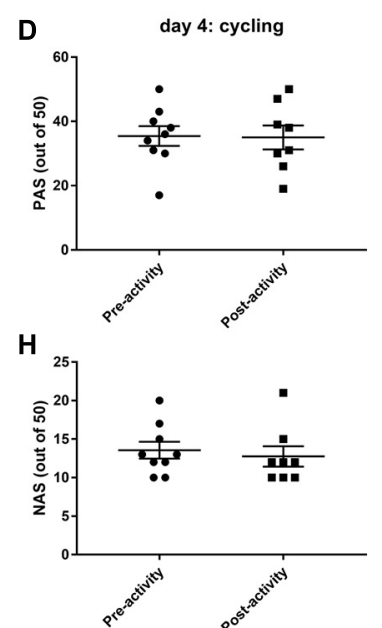

FIGURE 3 | Changes in postive (PAS, A-D) and negative (NAS, E-H) mood and emotions before and after 30 min activity (dancing, reading, singing or cycling) in nine healthy female volunteers. Data is presented as a scatter plot with mean \pm SEM. Data sets were compared by paired Student's $t$-test pre and post-activity $\left({ }^{* *} P<0.01,{ }^{* * *} P<0.001\right)$.
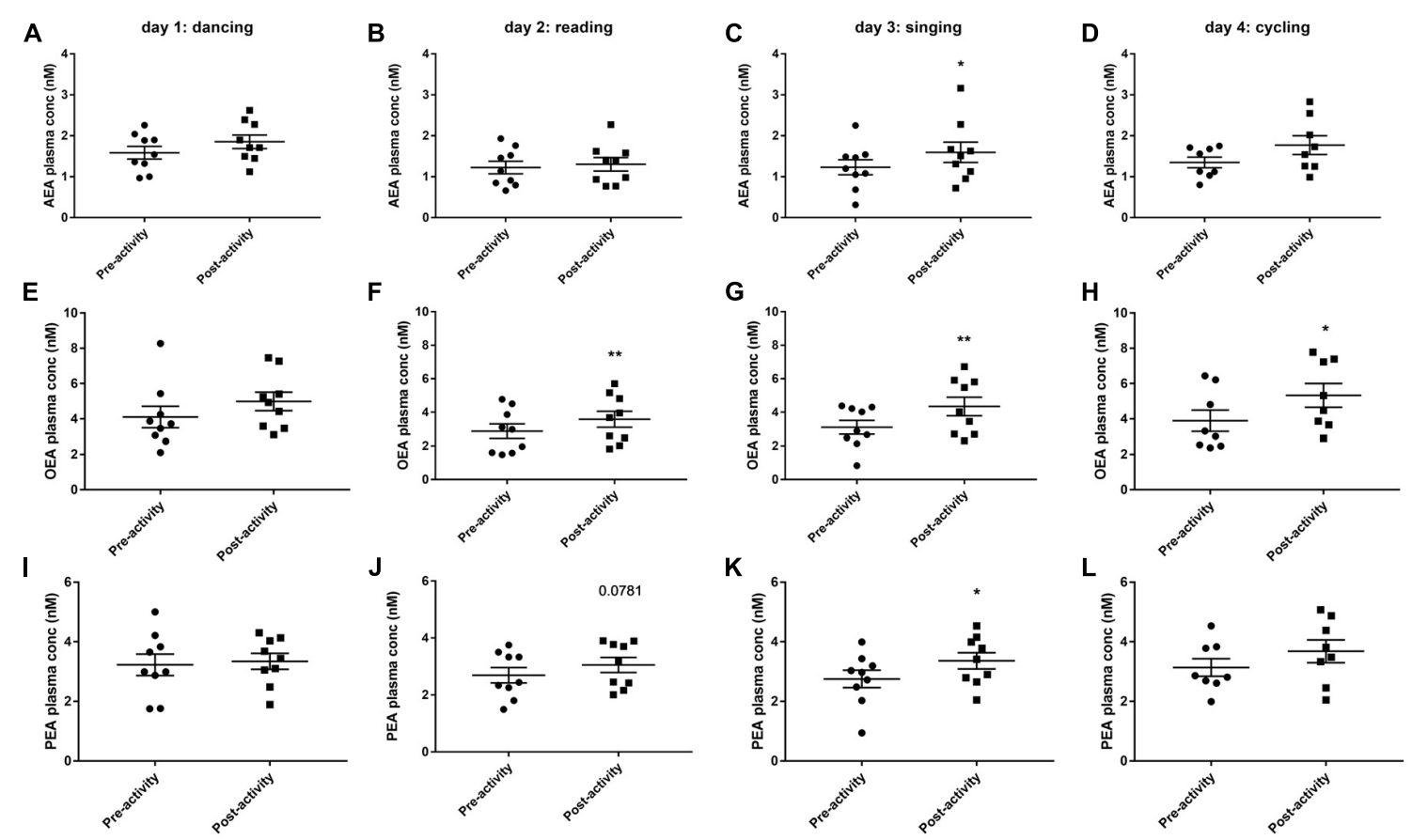

FIGURE 4 | Plasma endocannabinoid levels (AEA, anandamide, A-D; OEA, oleoylethanolamine, E-H; PEA, palmitoylethanolamine, I-L) before and after 30 min activity (dancing, reading, singing or cycling) in nine healthy female volunteers. Data is presented as a scatter plot with mean \pm SEM. Data sets were compared by paired Student's $t$-test pre and post-activity $\left({ }^{*} P<0.05,{ }^{* *} P<0.01\right)$.

(Hesselink and Hekker, 2012). Therefore, it could be beneficial to increase levels of PEA via activities such as singing, to promote neuroprotection, analgesia and reduce inflammation. It is also important to note that increasing OEA and PEA can indirectly increase AEA responses by the entourage effect by competitive inhibition of AEA degradation by fatty acid amide hydrolase (FAAH; Di Marzo et al., 2001; Costa et al., 2008; Ho et al., 2008). Overall, singing could be a valuable activity in patient populations that suffer with dysfunctions in psychological well-being and struggle to participate in aerobic/moderate intensity exercise.

Cycling resulted in a significant increase in OEA, and in a trend for increases in both AEA and PEA. These changes corresponded with a decrease in participants desire to eat and 


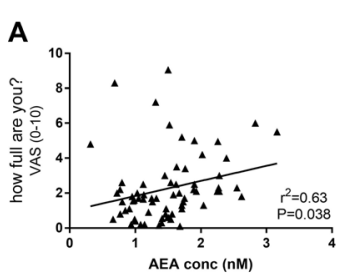

E

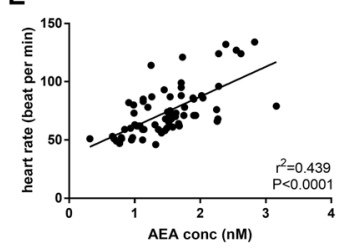

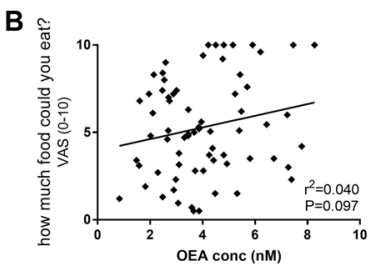

$\mathbf{F}$

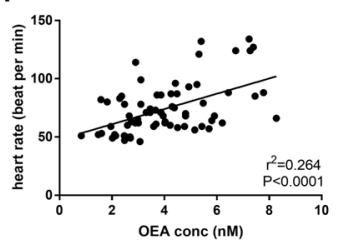

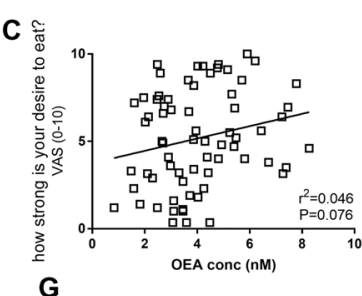
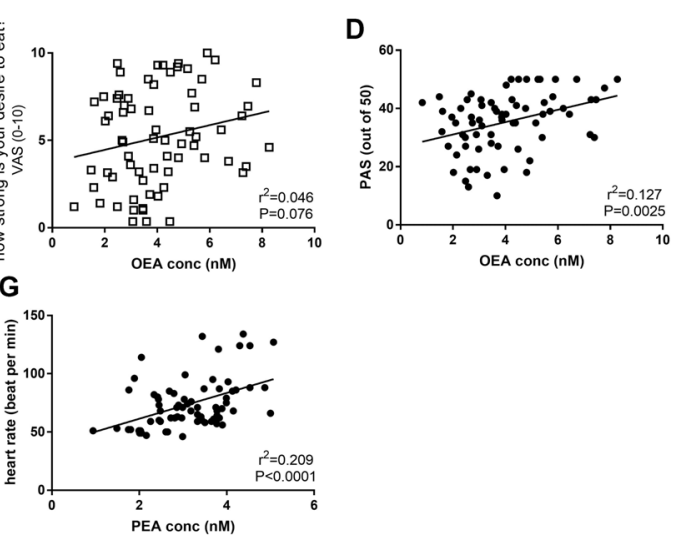

FIGURE 5 | Correlations between plasma eCBs levels and appetite (A-C), mood (D) and HR (E-G) in healthy female volunteers when measured pre or post-activities and analyzed by linear regression.

how hungry they felt. These data are consistent with results from a previous study where plasma OEA levels were significantly increased after $30 \mathrm{~min}$ of cycling in 16 male non-smokers with a mean age of 22.9 years (Cedernaes et al., 2016). Our data did not show that cycling positively affected mood (no increase in PAS or decrease in NAS). Brellenthin et al. (2017) showed that acute aerobic exercise (both prescribed and preferred) resulted in positive mood outcomes in individuals capable of a range of levels of physical activity, as well as showing modulation of the eCB system. Interestingly, the group that undertook their "preferred exercise" had the best effect in reducing anxiety and improving mood. In the present study, singing by participants recruited from a choir support these observations, suggesting that the eCB system is not only responsible for the motivation for exercise (i.e., reward driven), but also the pleasure associated with an activity that an individual enjoys. It would also have been interesting if another group had been included (i.e. not recruited from a choir) to directly assess the concept of preferred vs. prescribed activity and to confirm that carrying out an activity that is "pleasurable" to an individual is an important factor in the psychological benefits of exercise and other related activities. Subjects were also not asked to rate how much they enjoyed each of the activities, this would have been an interesting endpoint to assess to what degree the participant's moods were influenced by how much they liked a particular activity and should be considered in future study. These factors would also have provided further evidence to why individuals in this study failed to experience positive mood changes or significant increases in AEA post cycling; compared with the study by Heyman et al. (2012) where increases in AEA were seen in well-trained cyclists, who presumably enjoy cycling.

Exercise intensity may be another factor explaining the lack of AEA increases in our participants. Brellenthin et al. (2017) showed that the greatest increases in 2-AG and AEA were seen in the higher intensity exercise group. Sparling et al. (2003) also showed significant increases in AEA when participants reached 70\%-80\% max HR. According to Gulati et al. (2010), maximum HR for women is calculated as $206-(0.88 \times$ age of patient $)$. As the average age of our participants was 61 years, their average maximum HR (max HR) is approximately $154 \mathrm{bpm}$, meaning their $70 \%-80 \%$ max HR should be $107-123$ bpm. Cycling was the only activity that almost reached this (average $102 \mathrm{bpm}$ immediately post exercise) and dancing resulted in an average HR of $95 \mathrm{bpm}$ (immediately post exercise). This could suggest that our activities may not have been intense enough to elicit significant changes in circulating eCBs.

A number of studies have shown that dance is an effective therapy in improving mood (including mild depression), enhancing social interactions, boosting self-confidence, as well as improving physical activity (Akandere and Demir, 2011; Kiepe et al., 2012; Meekums et al., 2015). In one study, dancing caused an increase in plasma serotonin levels and a decrease in negative psychological symptoms in a group of 20 female adolescents with mild depression, compared to 20 control subjects (Jeong et al., 2005). We found post activity that there was a significant decrease in negative emotions following $30 \mathrm{~min}$ of dancing. It should be acknowledged that the decrease in negative emotions could also be because this was the activity undertaken on day 1 and participants had higher NAS scores before starting the study. Although there was a trend in increasing levels of AEA and OEA levels post-activity, this did not reach significance. Our results suggest that dancing did not effectively increase eCB levels or improve mood, however this could be because they were unfamiliar with the class, therefore not finding it as enjoyable as singing as this was more familiar to them, or that the class was not at a high enough intensity to produce changes in $\mathrm{eCB}$ levels. It should also be noted that our participants were older than those previously studied, and there could be an age-related decline in the eCB response to exercise.

Reading was used as a control activity to assess baseline eCB levels and mood. We found that reading was the only activity that increased participants desire to eat but had little impact on overall fullness or actual hunger and was correlated to increases in OEA post activity. Reading also decreased the ratings for positive mood and emotions. In hindsight, because subjects were unaware of the task, the activity set-up looked 
like they were about to take an exam, which may have resulted in unforeseen heightened anxiety levels. Recent studies have implicated the eCB system as a possible mediator of hedonic vs. homeostatic eating response to the consumption of food (as a reward) as well as acute stress and anxiety (Matias et al., 2006; Monteleone et al., 2015, 2017). Dlugos et al. (2012) showed that AEA, PEA and OEA were all increased in serum in response to stress. They also found that higher levels of AEA at baseline, associated with decreased levels of anxiety. Furthermore, a common phenomenon is that typically negative emotions, particularly boredom, stress and depressive emotions increase our desire to eat in order to increase positive emotions (Koball et al., 2012; Yau and Potenza, 2013; Moynihan et al., 2015). These factors could explain the elevated levels of OEA post activity and lower PAS scores.

A limitation of our study is that participants already had very low negative affect scores and high positive affect scores. This suggests that the individuals that took part in the study were generally happy and positive and there was therefore little room for mood to be further improved. It would therefore be interesting in future work to see the effects of these same activities on individuals that exhibit depressive, or anxious behavior in order to see greater differences in negative emotional responses. Intensity of a physical activity has also been shown to influence exercise induced increases in eCB levels. Raichlen et al. (2013) built on previous work showing that eCBs follow a U-shaped curve, with moderate level activity resulting in the biggest increase in eCB levels (Berger and Motl, 2000). This trend in eCB levels is also correlated with mood as the positive emotional state post exercise is not experienced at very low or very high intensities (Berger and Motl, 2000). As all the participants were unfamiliar to the activities they carried out, a lot of their focus would have been on "mastering" the class rather than actually enjoying it in the moment.

It can also not be overlooked that this study only recruited healthy female volunteers. Evidence from animal studies has already shown distinct sexual dimorphism in the eCB system, particularly in $\mathrm{CB}_{1}$ expression and activation (Reich et al., 2009; Mateos et al., 2011; Dias-Rocha et al., 2018). Limited preliminary evidence from human studies have also shown variations in the eCB system between males and females (Cupini et al., 2006; Hill et al., 2008). Thus future study should look to establish whether

\section{REFERENCES}

Ahern, G. P. (2003). Activation of TRPV1 by the satiety factor oleoylethanolamide. J. Biol. Chem. 278, 30429-30434. doi: 10.1074/jbc.M305051200

Akandere, M., and Demir, B. (2011). The effect of dance over depression. Coll. Antropol. 35, 651-656.

Berger, B. G., and Motl, R. W. (2000). Exercise and mood: a selective review and synthesis of research employing the profile of mood states. J. Appl. Sport Psychol. 12, 69-92. doi: 10.1080/10413200008404214

Bramble, D. M., and Lieberman, D. E. (2004). Endurance running and the evolution of Homo. Nature 432, 345-352. doi: 10.1038/nature 03052

Brellenthin, A. G., Crombie, K. M., Hillard, C. J., and Koltyn, K. F. (2017). Endocannabinoid and mood responses to exercise in adults with varying activity levels. Med. Sci. Sports Exerc. 49, 1688-1696. doi: 10.1249/MSS. 0000000000001276 the effects observed in this study translate to male participants as well as females.

In conclusion, we found that activities other than running (singing, dancing and cycling) can increase plasma eCB levels. Singing was the only activity to increase plasma levels of AEA and improve positive mood outcomes, suggesting that singing in this group of volunteers was able to produce an endogenous "high." This is interesting as the participants were recruited from a choir, suggesting that the enjoyment of an activity may influence their feeling of reward and the eCB response. This preliminary evidence suggests that activities like singing could be recommended to individuals suffering from mood disorders such as anxiety and depression, as well as a potential therapy for neurological and inflammatory disorders. Future research should consider an individual's preference to a particular activity, as this could be an important factor in influencing the eCB system, as well as being a factor in deciding appropriate therapy.

\section{AUTHOR CONTRIBUTIONS}

NS and SO'S wrote the article with contributions from all the other authors. SO'S, SM and NS carried out cardiovascular measurements, surveys and blood processing. SO'S processed the study data and performed the statistical analysis. CO and DB performed the $\mathrm{eCB}$ analysis on the plasma samples. $\mathrm{PH}$ carried out the blood draws from the subjects. VM developed the study with SO'S.

\section{FUNDING}

The eCB analysis was funded by BBC Studios. This work was supported by the Biotechnology and Biological Sciences Research Council (grant number BB/M008770/1).

\section{ACKNOWLEDGMENTS}

We would like to thank the participants for taking part in this study, and the BBC Studios "Trust Me I'm a Doctor" team for all their help in the organization of the study. We would also like to thank the singing, dance and cycling instructors who supervised the activities for their time and help.

Cedernaes, J., Fanelli, F., Fazzini, A., Pagotto, U., Broman, J.-E., Vogel, H. et al. (2016). Sleep restriction alters plasma endocannabinoids concentrations before but not after exercise in humans. Psychoneuroendocrinology 74, 258-268. doi: 10.1016/j.psyneuen.2016.09.014

Chapman, V., Kendall, D., and Sagar, D. R. (2009). "Cannabinoid receptor mediated analgesia: novel targets for chronic pain states," in Synaptic Plasticity in Pain, ed. M. Malcangio (New York, NY: Springer), 337-351.

Costa, B., Comelli, F., Bettoni, I., Colleoni, M., and Giagnoni, G. (2008). The endogenous fatty acid amide, palmitoylethanolamide, has anti-allodynic and anti-hyperalgesic effects in a murine model of neuropathic pain: involvement of CB1, TRPV1 and PPAR $\gamma$ receptors and neurotrophic factors. Pain 139, 541-550. doi: 10.1016/j.pain.2008.06.003

Cota, D. (2007). CB1 receptors: emerging evidence for central and peripheral mechanisms that regulate energy balance, metabolism, and cardiovascular health. Diabetes Metab. Res. Rev. 23, 507-517. doi: 10.1002/dmrr.764 
Cota, D., Marsicano, G., Tschöp, M., Grübler, Y., Flachskamm, C., Schubert, M., et al. (2003). The endogenous cennabinoid system affects energy balance via central orexigenic drive and peripheral lipogenesis. J. Clin. Invest. 112, 423-431. doi: $10.1172 /$ jci200317725

Crawford, J. R., and Henry, J. D. (2004). The positive and negative affect schedule (PANAS): construct validity, measurement propertiesand normative data in a large non-clinical sample. Br. J. Clin. Psychol. 43, 245-265. doi: 10.1348/0144665031752934

Cupini, L. M., Bari, M., Battista, N., Argirò, G., Finazzi-Agrò, A., Calabresi, P., et al. (2006). Biochemical changes in endocannabinoid system are expressed in platelets of female but not male migraineurs. Cephalalgia 26, 277-281. doi: 10.1111/j.1468-2982.2005.01031.x

De Petrocellis, L., and Di Marzo, V. (2009). An introduction to the endocannabinoid system: from the early to the latest concepts. Best Pract. Res. Clin. Endocrinol. Metab. 23, 1-15. doi: 10.1016/j.beem.2008.10.013

Devane, W. A., Hanus, L., Breuer, A., Pertwee, R. G., Stevenson, L. A., Griffin, G., et al. (1992). Isolation and structure of a brain constituent that binds to the cannabinoid receptor. Science 258, 1946-1949. doi: 10.1126/science.1470919

Di Marzo, V., Melck, D., Orlando, P., Bisogno, T., Zagoory, O., Bifulco, M., et al. (2001). Palmitoylethanolamide inhibits the expression of fatty acid amide hydrolase and enhances the anti-proliferative effect of anandamide in human breast cancer cells. Biochem. J. 358, 249-255. doi: 10.1042/0264-6021:3580249

Dias-Rocha, C. P., Almeida, M. M., Santana, E. M., Costa, J. C. B., Franco, J. G., Pazos-Moura, C. C., et al. (2018). Maternal high-fat diet induces sex-specific endocannabinoid system changes in newborn rats and programs adiposity, energy expenditure and food preference in adulthood. J. Nutr. Biochem. 51, 56-68. doi: 10.1016/j.jnutbio.2017.09.019

Dietrich, A., and McDaniel, W. F. (2004). Endocannabinoids and exercise. Br. J. Sports Med. 38, 536-541. doi: 10.1136/bjsm.2004.011718

Dlugos, A., Childs, E., Stuhr, K. L., Hillard, C. J., and de Wit, H. (2012). Acute stress increases circulating anandamide and other $\mathrm{N}$-acylethanolamines in healthy humans. Neuropsychopharmacology 37, 2416-2427. doi: 10.1038/npp.2012.100

Esposito, E., and Cuzzocrea, S. (2013). Palmitoylethanolamide in homeostatic and traumatic central nervous system injuries. CNS Neurol. Disord. Drug Targets 12, 55-61. doi: 10.2174/1871527311312010010

Fu, J., Gaetani, S., Oveisi, F., Lo Verme, J., Serrano, A., Rodríguez De Fonseca, F., et al. (2003). Oleylethanolamide regulates feeding and body weight through activation of the nuclear receptor PPAR- $\alpha$. Nature 425, 90-93. doi: $10.1038 /$ nature 01921

Fuss, J., Bindila, L., Wiedemann, K., Auer, M. K., Briken, P., and Biedermann, S. V. (2017). Masturbation to orgasm stimulates the release of the endocannabinoid 2-arachidonoylglycerol in humans. J. Sex. Med. 14, 1372-1379. doi: 10.1016/j. jsxm.2017.09.016

Galan-Rodriguez, B., Suarez, J., Gonzalez-Aparicio, R., Bermudez-Silva, F. J., Maldonado, R., Robledo, P., et al. (2009). Oleoylethanolamide exerts partial and dose-dependent neuroprotection of substantia nigra dopamine neurons. Neuropharmacology 56, 653-664. doi: 10.1016/j.neuropharm.2008.11.006

Gulati, M., Shaw, L. J., Thisted, R. A., Black, H. R., Bairey Merz, C. N., and Arnsdorf, M. F. (2010). Heart rate response to exercise stress testing in asymptomatic women: the St. James women take heart project. Circulation 122, 130-137. doi: 10.1161/CIRCULATIONAHA.110.939249

Hahn, A. H., Merullo, D. P., Spool, J. A., Angyal, C. S., Stevenson, S. A., and Riters, L. V. (2017). Song-associated reward correlates with endocannabinoidrelated gene expression in male European starlings (Sturnus vulgaris). Neuroscience 346, 255-266. doi: 10.1016/j.neuroscience.2017.01.028

Hansen, H. S., Moesgaard, B., Hansen, H. H., Petersen, G. (2000). $N$-Acylethanolamines and precursor phospholipids-relation to cell injury. Chem. Phys. Lipids 108, 135-150. doi: 10.1016/s0009-3084(00)00192-4

Hesselink, J. M., and Hekker, T. A. (2012). Therapeutic utility of palmitoylethanolamide in the treatment of neuropathic pain associated with various pathological conditions: a case series. J. Pain Res. 5, 437-442. doi: 10.2147/jpr.s32143

Heyman, E., Gamelin, F. X., Goekint, M., Piscitelli, F., Roelands, B., Leclair, E., et al. (2012). Intense exercise increases circulating endocannabinoid and BDNF levels in humans-possible implications for reward and depression. Psychoneuroendocrinology 37, 844-851. doi: 10.1016/j.psyneuen.2011.09.017

Hill, M. N., Miller, G. E., Ho, W. S., Gorzalka, B. B., and Hillard, C. J. (2008). Serum endocannabinoid content is altered in females with depressive disorders: a preliminary report. Pharmacopsychiatry 41, 48-53. doi: 10.1055/s-2007993211

Ho, W.-SV., Barrett, D. A., and Randall, M. D. (2008). 'Entourage' effects of $N$-palmitoylethanolamide and $N$-oleoylethanolamide on vasorelaxation to anandamide occur through TRPV1 receptors. Br. J. Pharmacol. 155, 837-846. doi: 10.1038/bjp.2008.324

Jeong, Y.-J., Hong, S.-C., Lee, M. S., Park, M.-C., Kim, Y.-K., and Suh, C.M. (2005). Dance movement therapy improves emotional responses and modulates neurohormones in adolescents with mild depression. Int. J. Neurosci. 115, 1711-1720. doi: 10.1080/00207450590958574

Kang, J., Scholp, A., and Jiang, J. J. (2017). A review of the physiological effects and mechanisms of singing. J. Voice 32, 390-395. doi: 10.1016/j.jvoice.2017. 07.008

Karwad, M. A., Macpherson, T., Wang, B., Theophilidou, E., Sarmad, S., Barrett, D. A., et al. (2017). Oleoylethanolamine and palmitoylethanolamine modulate intestinal permeability in vitro via TRPV1 and PPAR $\alpha$. FASEB J. 31, 469-481. doi: 10.1096/fj.201500132

Keppel Hesselink, J. M. (2012). New targets in pain, non-neuronal cells, and the role of palmitoylethanolamide. Open Pain J. 5, 12-23. doi: 10.2174/1876386301205010012

Kiepe, M. S., Stöckigt, B., and Keil, T. (2012). Effects of dance therapy and ballroom dances on physical and mental illnesses: a systematic review. Arts Psychother. 39, 404-411. doi: 10.1016/j.aip.2012.06.001

Klein, C., Hill, M. N., Chang, S. C., Hillard, C. J., and Gorzalka, B. B. (2012). Circulating endocannabinoid concentrations and sexual arousal in women. J. Sex. Med. 9, 1588-1601. doi: 10.1111/j.1743-6109.2012.02708.x

Koball, A. M. Meers, M. R., Storfer-Isser, A., Domoff, S. E., and MusherEizenman, D. R. (2012). Eating when bored: revision of the emotional eating scale with a focus on boredom. Health Psychol. 31, 521-524. doi: 10.1037/a00 25893

Kreutz, G., Bongard, S., Rohrmann, S., Hodapp, V., and Grebe, D. (2004). Effects of choir singing or listening on secretory immunoglobulin A, cortisol, and emotional state. J. Behav. Med. 27, 623-635. doi: 10.1007/s10865-00 4-0006-9

Lo Verme, J., Fu, J., Astarita, G., La Rana, G., Russo, R., Calignano, A., et al. (2005a). The nuclear receptor peroxisome proliferator-activated receptor$\alpha$ mediates the anti-inflammatory actions of palmitoylethanolamide. Mol. Pharmacol. 67, 15-19. doi: 10.1124/mol.104.006353

Lo Verme, J., Gaetani, S., Fu, J., Oveisi, F., Burton, K., and Piomelli, D. (2005b). Regulation of food intake by oleoylethanolamide. Cell. Mol. Life Sci. 62, 708-716. doi: 10.1007/s00018-004-4494-0

Mateos, B., Borcel, E., Loriga, R., Luesu, W., Bini, V., Llorente, R., et al. (2011). Adolescent exposure to nicotine and/or the cannabinoid agonist CP 55,940 induces gender-dependent long-lasting memory impairments and changes in brain nicotinic and CB1cannabinoid receptors. J. Psychopharmacol. 25, 1676-1690. doi: 10.1177/0269881110370503

Matias, I., Gonthier, M.-P., Orlando, P., Martiadis, V., De Petrocellis, L., Cervino, C., et al. (2006). Regulation, function, and dysregulation of endocannabinoids in models of adipose and $\beta$-pancreatic cells and in obesity and hyperglycemia. J. Clin. Endocrinol. Metab. 91, 3171-3180. doi: 10.1210/jc. 2005-2679

Mechoulam, R., Ben-Shabat, S., Hanus, L., Ligumsky, M., Kaminski, N. E., Schatz, A. R., et al. (1995). Identification of an endogenous 2-monoglyceride, present in canine gut, that binds to cannabinoid receptors. Biochem. Pharmacol. 50, 83-90. doi: 10.1016/0006-2952(95)00109-d

Meekums, B., Karkou, V., and Nelson, E. A. (2015). Dance movement therapy for depression. Cochrane Database Syst. Rev. 2:CD009895. doi: 10.1002/14651858. CD009895

Monteleone, A. M., Di Marzo, V., Aveta, T., Piscitelli, F., Dalle Grave, R., Scognamiglio, P., et al. (2015). Deranged endocannabinoid responses to hedonic eating in underweight and recently weight-restored patients with anorexia nervosa. Am. J. Clin. Nutr. 101, 262-269. doi: 10.3945/ajcn.114.096164

Monteleone, A. M., Piscitelli, F., Dalle Grave, R., El Ghoch, M., Di Marzo, V., Maj, M., et al. (2017). Peripheral endocannabinoid responses to hedonic eating in binge-eating disorder. Nutrients 9:E1377. doi: 10.3390/nu91 21377

Monteleone, P., Piscitelli, F., Scognamiglio, P., Monteleone, A. M., Canestrelli, B., Di Marzo, V., et al. (2012). Hedonic eating is associated with increased 
peripheral levels of ghrelin and the endocannabinoid 2-arachidonoyl-glycerol in healthy humans: a pilot study. J. Clin. Endocrinol. Metab. 97, E917-E924. doi: 10.1210/jc.2011-3018

Moynihan, A. B., van Tilburg, W. A. P., Igou, E. R., Wisman, A., Donnelly, A. E., and Mulcaire, J. B. (2015). Eaten up by boredom: consuming food to escape awareness of the bored self. Front. Psychol. 6:369. doi: 10.3389/fpsyg.2015. 00369

Okamoto, Y., Morishita, J., Tsuboi, K., Tonai, T., and Ueda, N. (2004). Molecular characterization of a phospholipase D generating anandamide and its congeners. J. Biol. Chem. 279, 5298-5305. doi: 10.1074/jbc.m3066 42200

Pearce, E., Launay, J., Machin, A., and Dunbar, R. I. (2016). Is group singing special? Health, well-being and social bonds in community-based adult education classes. J. Community Appl. Soc. Psychol. 26, 518-533. doi: $10.1002 /$ casp. 2278

Raichlen, D. A., Foster, A. D., Gerdeman, G. L., Seillier, A., and Giuffrida, A. (2012). Wired to run: exercise-induced endocannabinoid signaling in humans and cursorial mammals with implications for the 'runner's high'. J. Exp. Biol. 215, 1331-1336. doi: 10.1242/jeb.063677

Raichlen, D. A., Foster, A. D., Seillier, A., Giuffrida, A., and Gerdeman, G. L. (2013). Exercise-induced endocannabinoid signaling is modulated by intensity. Eur. J. Appl. Physiol. 113, 869-875. doi: 10.1007/s00421-012-2495-5

Reagon, C., Gale, N., Enright, S., Mann, M., and van Deursen, R. (2016). A mixedmethod systematic review to investigate the effect of group singing on health related quality of life. Complement. Ther. Med. 27, 1-11. doi: 10.1016/j.ctim. 2016.03.017

Reich, C. G., Taylor, M. E., and McCarthy, M. M. (2009). Differential effects of chronic unpredictable stress on hippocampal CB1 receptors in male and female rats. Behav. Brain Res. 203, 264-269. doi: 10.1016/j.bbr.2009.05.013

Richardson, D., Ortori, C. A., Chapman, V., Kendall, D. A., and Barrett, D. A. (2007). Quantitative profiling of endocannabinoids and related compounds in rat brain using liquid chromatography-tandem electrospray ionization mass spectrometry. Anal. Biochem. 360, 216-226. doi: 10.1016/j.ab.2006. 10.039

Riters, L. V., Spool, J. A., Merullo, D. P., and Hahn, A. H. (2017). Song practice as a rewarding form of play in songbirds. Behav. Processes doi: 10.1016/j.beproc. 2017.10.002 [Epub ahead of print].

Schladt, T. M., Nordmann, G. C., Emilius, R., Kudielka, B. M., de Jong, T. R., and Neumann, I. D. (2017). Choir versus solo singing: effects on mood, and salivary oxytocin and cortisol concentrations. Front. Hum. Neurosci. 11:430. doi: 10.3389/fnhum.2017.00430
Sparling, P. B., Giuffrida, A., Piomelli, D., Rosskopf, L., and Dietrich, A. (2003). Exercise activates the endocannabinoid system. Neuroreport 14, 2209-2211. doi: 10.1097/00001756-200312020-00015

Starowicz, K., Makuch, W., Osikowicz, M., Piscitelli, F., Petrosino, S., Di Marzo, V., et al. (2012). Spinal anandamide produces analgesia in neuropathic rats: possible $\mathrm{CB}_{1}$ - and TRPV1-mediated mechanisms. Neuropharmacology 62, 1746-1755. doi: 10.1016/j.neuropharm.2011.11.021

Tarr, B., Launay, J., and Dunbar, R. I. M. (2016). Silent disco: dancing in synchrony leads to elevated pain thresholds and social closeness. Evol. Hum. Behav. 37, 343-349. doi: 10.1016/j.evolhumbehav.2016.02.004

Tsatsoulis, A., and Fountoulakis, S. (2006). The protective role of exercise on stress system dysregulation and comorbidities. Ann. N Y Acad. Sci. 1083, 196-213. doi: 10.1196/annals.1367.020

Watson, D., Clark, L. A., and Tellegen, A. (1988). Development and validation of brief measures of positive and negative affect: the PANAS scales. J. Pers. Soc. Psychol. 54, 1063-1070. doi: 10.1037/0022-3514.54.6.1063

Yang, L.-C., Guo, H., Zhou, H., Suo, D.-Q., Li, W.-J., Zhou, Y., et al. (2015). Chronic oleoylethanolamide treatment improves spatial cognitive deficits through enhancing hippocampal neurogenesis after transient focal cerebral ischemia. Biochem. Pharmacol. 94, 270-281. doi: 10.1016/j.bcp.2015.02.012

Yau, Y. H., and Potenza, M. N. (2013). Stress and eating behaviors. Minerva Endocrinol. 38, 255-267.

Zajenkowski, M., Jankowski, K. S., and Koata, D. (2015). Let's dance-feel better! Mood changes following dancing in different situations. Eur. J. Sport Sci. 15, 640-646. doi: 10.1080/17461391.2014.969324

Zhou, Y., Yang, L., Ma, A., Zhang, X., Li, W., Yang, W., et al. (2012). Orally administered oleoylethanolamide protects mice from focal cerebral ischemic injury by activating peroxisome proliferator-activated receptor $\alpha$. Neuropharmacology 63, 242-249. doi: 10.1016/j.neuropharm.2012.03.008

Conflict of Interest Statement: The authors declare that the research was conducted in the absence of any commercial or financial relationships that could be construed as a potential conflict of interest.

Copyright (C) 2018 Stone, Millar, Herrod, Barrett, Ortori, Mellon and O’Sullivan. This is an open-access article distributed under the terms of the Creative Commons Attribution License (CC BY). The use, distribution or reproduction in other forums is permitted, provided the original author(s) and the copyright owner(s) are credited and that the original publication in this journal is cited, in accordance with accepted academic practice. No use, distribution or reproduction is permitted which does not comply with these terms. 